\title{
Die Sextussprüche und ihre Verwandten
}

Eingeleitet, übersetzt u. mit interpretierenden Essays versehen v. Wilfried Eisele, Yury Arzhanov, Michael Durst u. Thomas Pitour. Hrsg. v. Wilfried Eisele

Die Sextussprüche und ihre Verwandten

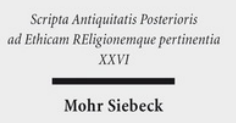

2015. XIV, 489 Seiten. SAPERE XXVI

SBN 978-3-16-156429-1

DOI 10.1628/978-3-16-156429-1

eBook PDF

ISBN 978-3-16-153657-1

Leinen $114,00 €$
In Antike und Mittelalter waren Sammlungen von Sprüchen (Gnomen/Sentenzen) eine beliebte Form der Gebrauchsliteratur. Als Texte erhoben sie keinen hohen literarischen Anspruch. Das heißt aber nicht, dass ihr Inhalt immer leicht zu verstehen wäre. Oft handelt es sich um sprachlich verdichtete Einsichten und Ermahnungen, die weit mehr voraussetzen als sie sagen. Das öffnet ein weites Feld der Interpretation und Relecture, die in der offenen Form der Sammlung vor allem durch Vermehrung, Verminderung oder Umgruppierung des Spruchmaterials stattfindet. Die dem Philosophen Sextus zugeschriebenen Sprüche stellen ein bemerkenswertes Beispiel für eine christlich überarbeitete Spruchsammlung der Kaiserzeit dar. Sie haben pythagoreische Vorläufer und wirken über Evagrius Ponticus im christlichen Mönchtum fort. Der Band zeichnet diese Entwicklungslinien nach.

Wilfried Eisele Geboren 1971; Studium der Kath. Theologie und der Philosophie in Tübingen, Jerusalem und Paris; 2002 Dr. theol.; 2010 Habilitation (Neues Testament); 2010 Lehrstuhlvertretung für Neues Testament in Mainz; 2010-11 Professor für Neutestamentliche Wissenschaften in Chur; seit 2011 Professor für Zeit- und Religionsgeschichte des Neuen Testaments in Münster.

Yury Arzhanov ist wissenschaftlicher Mitarbeiter im Projekt "Glossarium Graeco-Arabicum“ an der Ruhr-Universität-Bochum und unterrichtet syrische Sprache im Institut für Orientalistik der RUB. Seine Forschungsinteressen liegen im Bereich der syrischen Übersetzungen der griechischen philosophischen und wissenschaftlichen Schriften mit Schwerpunkt in der syrischen Rezeption der populären Ethik.

Michael Durst ist ordentlicher Professor für Kirchengeschichte und Patrologie an der Theologischen Hochschule Chur. Seine Forschungsschwerpunkte liegen im Bereich der lateinischen Großpatristik, vornehmlich Hilarius von Poitiers (Handschriftenforschung, Editionsprojekte), und der frühen Geschichte der Kirche im Gebiet der Schweiz, vor allem des Bistums Chur.

Thomas Pitour ist kath. Pfarrer in Munderkingen (Diözese Rottenburg- Stuttgart). Zuvor war er in Tübingen Assistent am Lehrstuhl für philosophische Grundfragen der Theologie.

Jetzt bestellen:

https://mohrsiebeck.com/buch/die-sextussprueche-und-ihre-verwandten-9783161564291?no cache=1 order@mohrsiebeck.com

Telefon: +49 (0)7071-923-17

Telefax: +49 (0)7071-51104 